\title{
Management of a Type II Dens Invaginatus with Regenerative Endodontic Therapy
}

\author{
Hana Bougatef ${ }^{1,2}$ Marouen Ouni $^{1,2}$ Ines Kallel ${ }^{1,2}$ Eya Moussaoui ${ }^{2,3}$ Oumaima Elleuch ${ }^{1,2}$ Nabiha Douki ${ }^{1,2}$
}

'Department of Conservative Dentistry and Endodontics, Department of Dental Medicine, EPS Sahloul, Sousse, Tunisia

${ }^{2}$ Faculty of Dental Medicine, Oral Health and Oro-Facial Rehabilitation Laboratory Research (LR12ES11), University of Monastir, 5019 Monastir, Tunisia

${ }^{3}$ Department of Oral Surgery, Department of Dental Medicine, EPS

Sahloul, Sousse, Tunisia
Address for correspondence: Hana Bougatef, Department of Conservative Dentistry and Endodontics, Department of Dental Medicine, EPS Sahloul, 4011 Sousse, Tunisia

E-mail: bougatef.hana@hotmail.com

\begin{abstract}
Dens invaginatus (DI) is an unusual tooth anomaly, resulting from an infolding of the dental papilla during tooth development. Root canal treatment of such teeth is challenging because of the difficulties associated with this type of malformation.

The purpose of this paper was to describe the management of Oehlers type II DI in an immature upper right canine associated with a latero-apical lesion and a sinus tract and to demonstrate that cone beam computed tomography (CBCT) and operator dental microscope are essential auxiliaries that help in avoiding errors in the diagnosis and treatment of such teeth.

We also aimed to highlight a novel method of regenerative endodontic treatment (RET) for immature necrotic teeth using Platelet-rich fibrin (PRF), a recently developed scaffold material, to overcome limitations associated with traditional endodontic treatment using an apical plug.

Keywords: Cone-beam computed tomography, dens invaginatus, immature tooth, platelet-rich fibrin, regenerative endodontic treatment
\end{abstract}

\section{Introduction}

Dens invaginatus (DI) is a developmental anomaly resulting from an invagination of the enamel organ into the dental papilla prior to the mineralization phase.[1] Maxillary lateral incisors are the most commonly affected teeth,[2] followed by maxillary central incisors, premolars, canines, and less often molars.[3]
Prevalence of DI varies depending on the invagination type. Type I is the most common, reaching a prevalence of $11.3 \%$, while types II and III are uncommon, accounting for $0.7 \%$ and $0.8 \%$ of cases, respectively,[4] with a 3:1 female predilection.[1]

The purpose of this paper was to detail the management of type II dens invaginatus in an immature necrotic permanent tooth using the revascularization

How to cite this article: Bougatef $\mathrm{H}$, Ouni M, Kallel I, Moussaoui E, Elleuch O, Douki N. Management of a Type II Dens Invaginatus with Regenerative Endodontic Therapy. J Pediatr Dent 2021;7(2):83-92 
approach with platelet-rich fibrin (PRF) as a scaffold material, and to discuss the clinical and radiological outcomes of this technique.

\section{Case Presentation}

A 15-year-old girl presented with a complaint of a twomonth recurrent swelling and pus discharge in her maxillary right anterior region. Her medical history was non-contributory. Extra-oral examination revealed no abnormality. Intra-oral examination showed a sinus tract over the labial alveolar mucosa associated with the right maxillary canine (Fig. 1). The tooth was tender to vertical percussion with normal mobility. The crown was free of caries or restorations, with an atypical morphology, involving a big crown compared to the left canine and a deep subgingival pit on the palatal aspect. Periodontal probing was $3 \mathrm{~mm}$ all around the tooth. Pulp sensibility testing did not yield any response.

Intra-oral periapical radiograph of the maxillary right canine showed an invagination structure in the cervical third of the root canal with a latero-apical radiolucent lesion on the mesial aspect of the tooth root, not extending to the apex. The tooth was immature with an open apex and a large root canal having thin radicular walls (Fig. 2). Diagnosis of DI was made. To confirm the type, a cone beam computed tomography (CBCT) examination was carried out.

The axial and coronal sections of CBCT revealed an abnormal crown morphology simulating the appearance of a tooth inside the affected tooth (Figs. 3a, b).

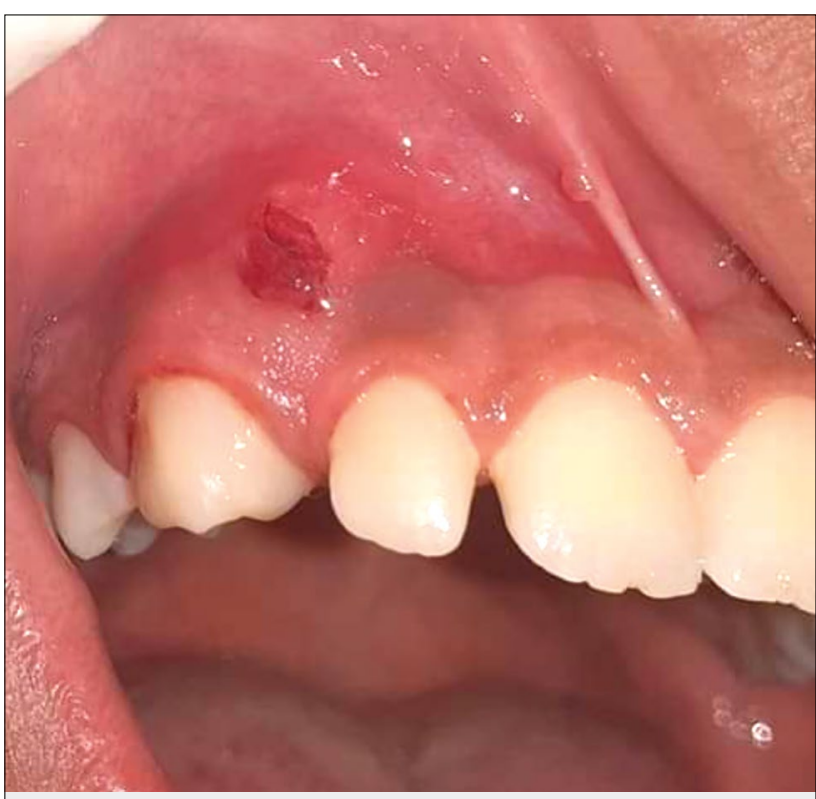

Figure 1. Intraoral view: fistulated periapical abcess in relation with the right maxillary canine
The sagittal section showed an abnormal root canal morphology with single root apex at the end of the main root canal and a latero-apical radiolucency (Fig. 3c).

CBCT examination confirmed the diagnosis of type II invagination, extending from the crown to the cervical third of the root, with no apparent communication with the main canal. Diagnosis of Oehler's type II DI with chronic apical periodontitis was made at the right maxillary canine.

Endodontic treatment and microscopic removal of DI were planned. The possibility of a revascularization with PRF was also suggested to the patient's parents. Thus, parents were informed about the treatment protocol and written informed consent was obtained.

Following local anesthesia and rubber dam setting, an endodontic access was performed. After pulp exposition, the main root canal was slightly negotiated with $\mathrm{K}$ files. Using dental operating microscope, the invaginated structure was totally removed by a long-tapered

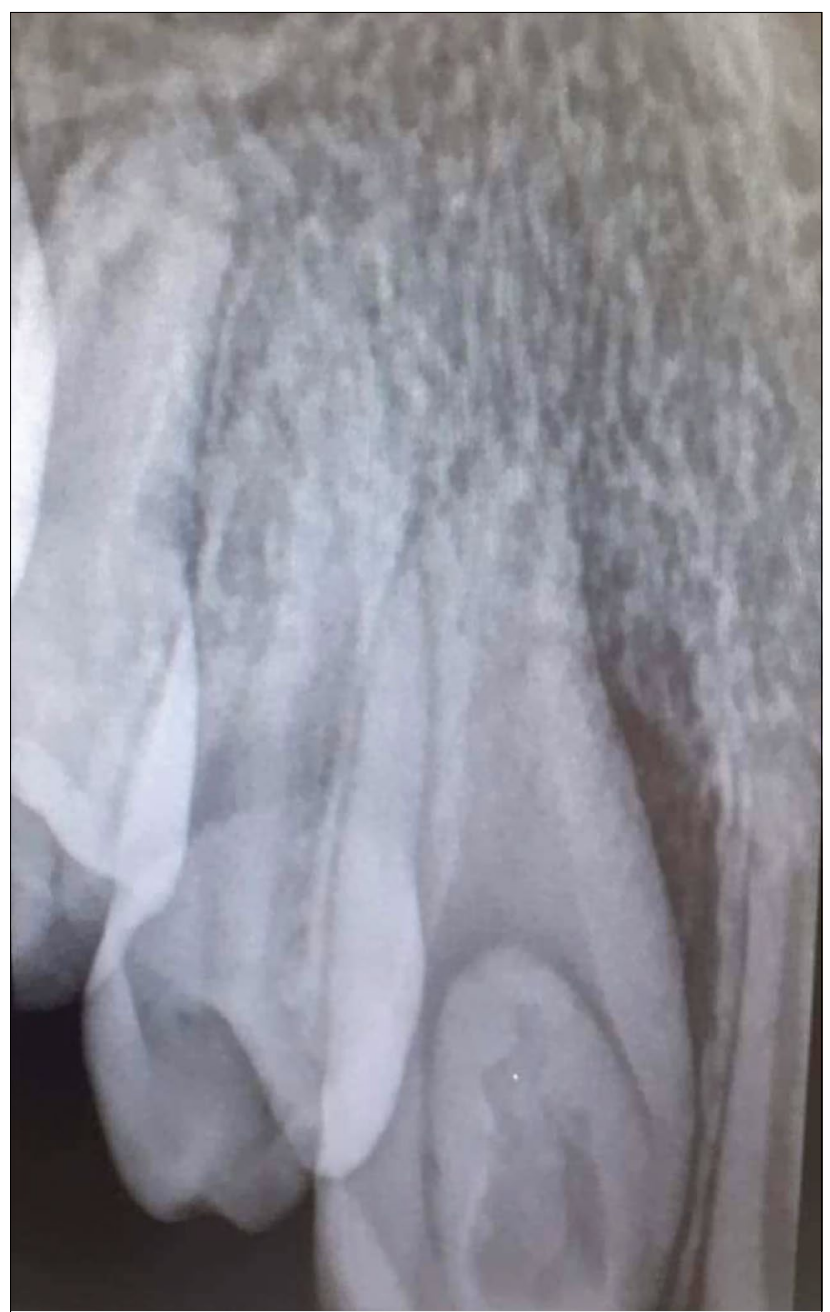

Figure 2. Periapical radiograph showing CL II Oehler's dens invaginatus and a latero-apical lesion 


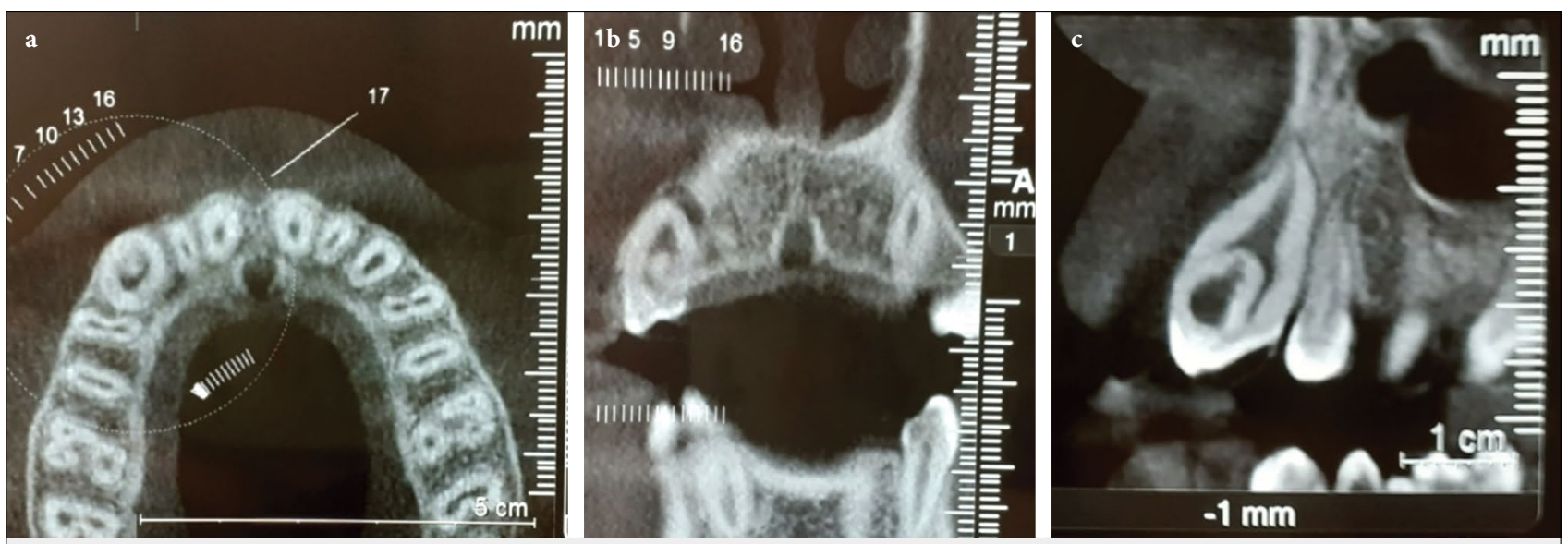

Figure 3. Axial slice (a) and Coronal slice (b) Sagittal slice (c) showing central odontoma in the coronal third of the root canal
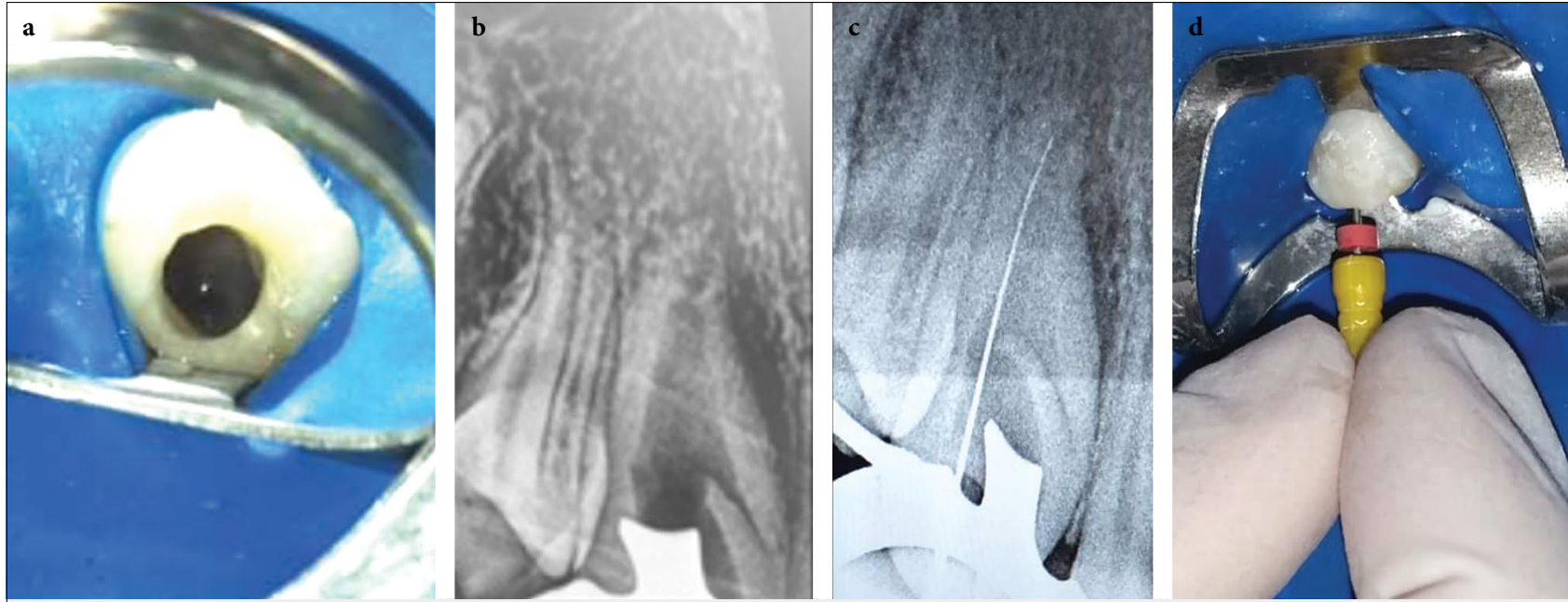

Figure 4. Clinical view (a), Periapical radiograph (b), after odontoma elimination and working length determination (c), Over instrumentation to induce bleeding $(\mathrm{d})$

bur with radiograph follow-up (Figs. 4a, b). The working length was determined using a periapical radiograph (Fig. 4c).

The root canal was subsequently irrigated with $2.5 \%$ sodium hypochlorite. Calcium hydroxide paste with normal saline as a vehicle was placed into the canal for two weeks with temporary coronal filling.

Due to the wide apical foramen (gauged at $60 \mathrm{~mm}$ diameter) and especially to the thin radicular walls, the tooth was very weak. Thus, after the patient's and parents' confirmation, a decision was taken to attempt the revascularization technique in order to provide apexogenesis and dentinal wall thickening.

At the two-week follow-up visit, the tooth was asymptomatic, and the sinus tract was resolved.

The access cavity was reopened under rubber dam isolation and the canal was copiously irrigated using saline to remove calcium hydroxide medication.
In the final irrigation sequence, $17 \%$ Ethylenediaminetetraacetic acid (EDTA) solution was applied with well-adapted master gutta percha cone and careful manual dynamic activation for 1 minute. Then, neutralization with normal saline solution, and final irrigation with sodium hypochlorite $2.5 \%$ activated with the same dynamic manual technique were performed. Finally, the canal space was dried with a paper point.

Intentional over instrumentation $(2-3 \mathrm{~mm})$ was conducted with $\mathrm{K}$-files \#20 to induce bleeding near the apical foramen to a level below the cemento-enamel junction (CEJ). Unfortunately, bleeding did not reach the CEJ (Fig. 4d).

In the meantime, for the preparation of PRF, $5 \mathrm{ml}$ of blood was drawn intravenously from the patient's forearm (antecubital vein) using an 18-gauge needle and it was collected in a sterile plastic vacuum tube without 


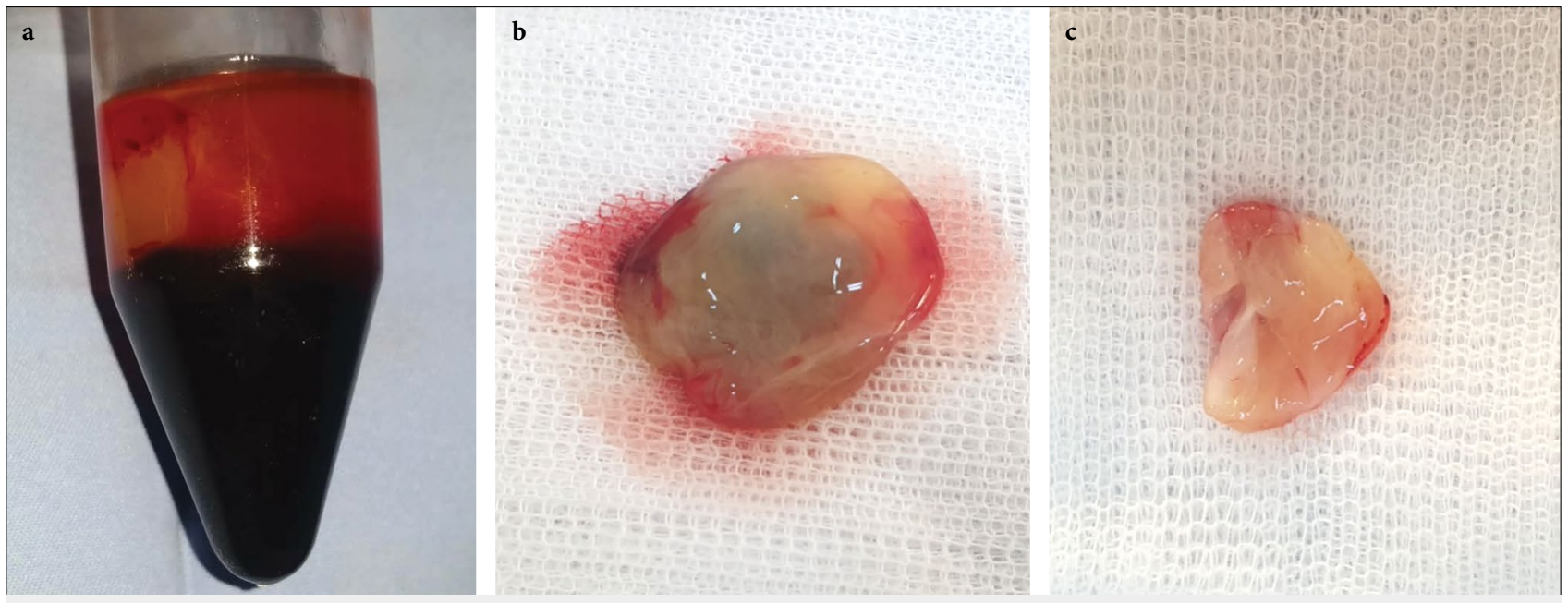

Figure 5. PRF preparation. Three layers obtained after centrifugation: platelet-poor plasma at the top (black arrow), platelet-rich fibrin in middle (yellow arrow), and red blood cells at the base (red arrow) (a), Platelet-rich fibrin clot (b) Platelet-rich fibrin membrane obtained after squeezing platelet-rich fibrin clot (c)

adding any anticoagulants. Then, the tube was immediately centrifuged in the hematology department under 3000 revolutions per minute for 15 minutes. After centrifugation, three layers were formed in the tube (Fig. 5a): 1. Top layer: Platelet Poor Plasma (PPP) - acellular straw-colored fluid

2. A middle layer: PRF clot

3. A bottom layer: Red Blood Cells (RBCs)

Sterile tweezers were inserted into the test tube to remove the PRF clot (Fig. 5b). The PRF gel was pressed inside the sterile dry gauze to squeeze out fluid, thus obtaining a membrane (Fig. 5c). The membrane was cut into small fragments using a scalpel blade and it was placed incrementally inside the canal using Machtou plugger (Fig. 6a). Then, Biodentine (Septodont, Saint Maur des Fosses, France) was placed directly over the PRF membrane. The access cavity was also filled with Biodentine and a periapical radiograph was taken to control the postoperative result (Fig. 6b).
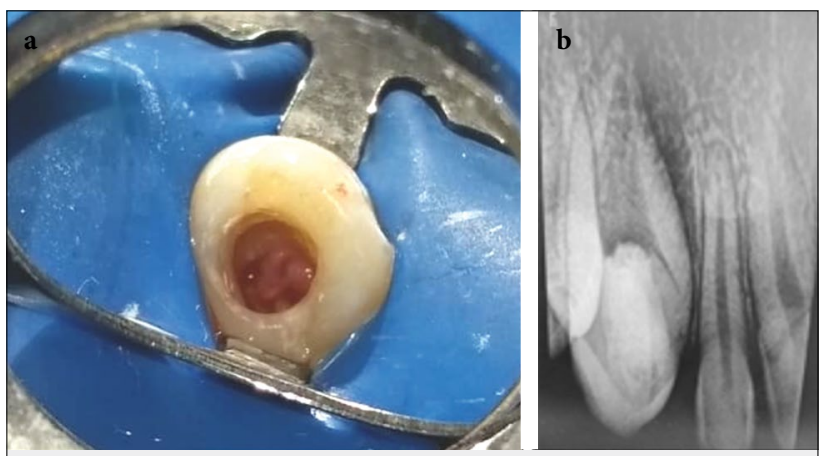

Figure 6. Platelet-rich fibrin membrane condensation in the root canal (a) radiographic control after Biodentine filling (b)
After five days, the patient was recalled replacing a 3-mm coronal Biodentine with composite resin. The patient was kept under observation and she was recalled at one, three, six, nine, and twelve months to evaluate the clinical and radiological evolution. At the 3-month follow-up visit, the tooth was asymptomatic. Periapical radiograph showed total disappearance of the latero-apical lesion (Fig. 7a). At the 8-month follow-up, the tooth was still asymptomatic. Periapical radiograph did not show any sign of radicular thickening (Fig. 7b).

\section{Discussion}

The clinical significance of DI consists in the high risk of oral bacterial contamination through the coronal
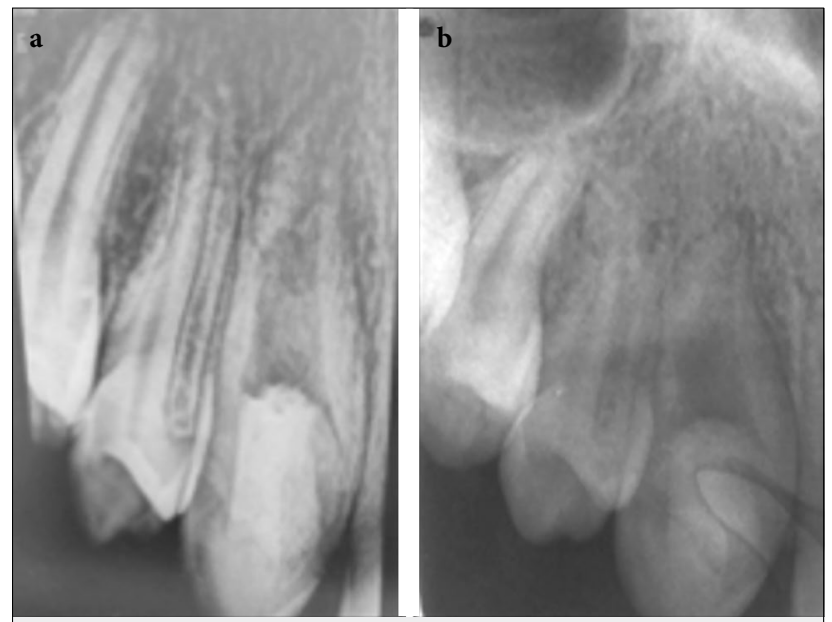

Figure 7. Periapical radiograph after three months showing latero-apical lesion healing (a) after eight months (b) 
aspect of the invagination (pit), leading to infection of the root canal system and to necrosis complication. [5]

According to Oehler's classification, type II is characterized by an invaginatus structure that invades the root with no communication with the periodontal ligament, but it remains confined as a blind sac, which may or may not have communication with the dental pulp.[6]

Clinically, the crown of a DI can have normal or unusual forms. It can have a conical, peg, or barrelshaped form. It can also present a greater buccal-lingual dimension or a talon cusp. A deep foramen cecum might be the most relevant coronal alteration of DI, susceptible to caries.[7]

In our case, the maxillary right canine presented a large mesio-distal dimension compared to the contralateral tooth with a deep palatal pit. Treatment planning of DI generally depends on the type of anomaly. To determine the complexity of the anomaly, radiographs at different angulations are well recommended.[8]

Radiographically, Oehler's type II DI, as in our case, shows a radiopaque invagination, equal in density to the enamel, extending from the cingulum to the root canal.[9] However, often, digital periapical radiographs may not reveal the type and degree of the invagination.[10] For this reason, the use of CBCT is important for a more precise examination of the tooth morphology and the root canals in all possible directions.[11] Indeed, it helps in the treatment planning and execution.[12]

Whenever DI is diagnosed, restorative prophylactic procedures, using adhesive materials to close communication with the oral environment, are recommended. Invagination may also be lined with Calcium Hydroxide to stimulate the formation of secondary dentin before sealing.[13]

Regular follow-up and periodic evaluation are necessary after prophylactic sealing of type II invagination. [13] In our case, the tooth was asymptomatic for many years. However, silent necrosis with a periapical complication was finally revealed. The patient did not receive any prophylactic treatment. In fact, late identification of the invagination may lead to pulp necrosis and periapical complication at an early age, mainly subsequent to the pulp contamination through the invagination space. These conditions have been reported to be the circumstances of DI identification.[14]

Endodontic management of a tooth with Oehler's type II DI is a great challenge considering the canal morphology and the complex anatomy due to the larger extension of the invagination, which may influence the root canal disinfection. $[15,16]$
In addition, given the major complication consisting in early pulp necrosis, an immature tooth with an open apex and weak dentinal walls should often be managed.[17] In the present case, diagnosis of chronic apical periodontitis was confirmed in the immature right maxillary canine. Following gauging, the wide apical foramen was $60 \mathrm{~mm}$ in diameter. In addition, periapical radiograph showed very thin root canal walls.

Various clinical approaches have been described for the management of Oehler's type II DI, including restorative procedures, nonsurgical endodontic treatment, removal of the invaginatus structure, apexification, pulp revascularization, endodontic surgery, intentional replantation, or even tooth extraction. [5] The surgical approach was reserved to orthograde endodontic treatment failures.[18]

In case of type II DI, invagination generally occurs in the pulp cavity and it is totally surrounded by the pulp tissue. Thus, adequate cleaning of the main root canal is complicated. Invagination is usually removed during endodontic treatment to facilitate disinfection and filling of the canal system. However, the removal may compromise the tooth structure.[14,19]

Thanks to the technological advances in endodontics, involving the use of specific ultrasonic tips, operating microscope and bioceramic cements, the clinician can make a predictable conventional endodontic treatment of type II DI.[20]

In fact, the use of microscopy can help in defining the access of the invagination and contribute to the subsequent preparations. [20] In the reported case, we proceeded for the removal of the invaginatus structure using a long-tapered bur under microscopic and radiographic control.

During endodontic treatment, the clinician should also be prudent. Indeed, minimal hand/rotary instrumentation is recommended in DI due to the lack of need to shape the root canal system and the presence of a risk to further weaken the tooth.[16]

Moreover, complete pulp space disinfection of DI is mandatory to promote healing of the affected periapical tissues. Sodium hypochlorite (5.25\%) as an irrigation solution and calcium hydroxide as an endodontic medication are recognized to be the gold standard to attain this purpose.[21]

The revascularization success of immature teeth with apical periodontitis depends on some success keys, involving root canal disinfection, scaffold placement in the canal for the growing tissues, and bacteria-tight sealing of the access cavity. 


\section{Root canal disinfection:}

It is well-proven that maintaining a high level of disinfection during this regenerative procedure in necrotic teeth is important to improve prognosis. In fact, residual bacterial biofilm and their products have been found to affect the differentiation capacity of the stem cells from the apical papillae.[22]

The most common disinfection techniques are irrigation with sodium hypochlorite $(\mathrm{NaOCl})$ and chlorhexidine (CHX), followed by disinfection with antimicrobial dressings, such as $\mathrm{Ca}(\mathrm{OH}) 2$, or antibiotic pastes, such as triple antibiotic paste (TAP).[23]

The disinfection effect of irrigation solutions and antibiotics ( $\mathrm{NaOCl}$, chlorhexidine, antibiotic) is concentration-dependant.

However, clinically, lower concentration of various endodontic medicaments and irrigation solutions is recommended to maintain the survival of stem cells from the apical papillae (SCAPs). High sodium hypochlorite concentration (5.25\%) is incriminated in inhibiting stem cell attachment to the dentin surface and it could be cytoxic.[22]

Haapasolo et al recommend a final rinse with $0.12 \%$ $\mathrm{CHX}$ in addition to $\mathrm{NaOCl}$ for the first appointment because of CHX's antimicrobial activity and its ability to extend this activity through the interaction with dentin.[24] However, for others, it is recommended to avoid it given that $\mathrm{CHX}$ has been reported to be cytotoxic to stem cells.[23]

Another irrigant has been suggested, EDTA (ethylenediaminetetraacetic acid) is also suggested as an irrigant. As a final solution, EDTA gentle irrigation is recommended to inhibit biofilm formation. [23]

Some authors have suggested that it reverses the deleterious effects of $\mathrm{NaOCl}$.[25] Concerning inter-appointment medication, triple antibiotic paste (TAP), double antibiotic paste (DAP), and calcium hydroxide $\mathrm{Ca}(\mathrm{OH}) 2$ are the most reported in the literature. TAP, consisting of minocycline, metronidazole and ciprofloxacin, is commonly applied during the regenerative procedures.[26]

Reports have shown that, when used as an interappointment medication, this paste is effective against many types of pathogens, especially those causing endodontic failures in addition to bacteria present in the deep layers of root canal dentin.[26] However, minocycline, as a constituent of TAP, is associated with dentin staining and reduction in tooth fracture resistance. $[27,28]$ Therefore, attempts to eliminate it and to apply DAP, consisting of ciprofloxacin and metronidazole, has been performed. Another formulation suggests replacing minocycline with amoxicillin or cefaclor as a modified TAP (mTAP).[29] It was proven in some studies, that all antibiotic preparations are toxic to the SCAP in a concentration-dependent manner.[30]

However, $\mathrm{Ca}(\mathrm{OH}) 2$ does not have any toxic effect on SCAP cells irrespective of the concentration in which it is used. In contrast, it results in proliferation of stem cells.[31]

It has unique properties, similar to EDTA solution, consisting in exposing the extracellular matrix and promoting the release of embedded bioactive molecules. [30] In fact, EDTA solution, used as a final irrigation, and water-based $\mathrm{Ca}(\mathrm{OH}) 2$ formulation, have been shown to release significant amounts of growth factors, such as TGF- $\beta$ that promotes osteogenic differentiation. [32,33] Therefore, $\mathrm{Ca}(\mathrm{OH}) 2$ has been suggested as the first choice of endodontic medicament.[31]

For this reason, in our case, we proceeded to improve disinfection with an inter-appointment medication based on $\mathrm{Ca}(\mathrm{OH}) 2$ for two weeks.

\section{Scaffold for Pulp Tissue Regeneration:}

Many studies have proven that the use of an appropriate scaffold is very essential to initiate differentiation and growth of new cells from the periapical area.[26] Apart from natural blood clot, various authors have suggested different scaffolds, such as collagen, PlateletRich-Plasma (PRP), PRF, synthetic polymers, and bioactive ceramics for the revascularization process.[34]

The use of PRF as a scaffold material to induce root growth in immature necrotic teeth is a new vista in the regenerative world. [35] It has been suggested that PRF is able to attract stem cells from the surrounding periapical tissues and to cause both hard and soft tissues regrowth.[36,37]

Among these cells, dental pulp cells present in the apical papilla remain vital and may differentiate into odontoblast-like cells under the influence of Hertwig's epithelial root sheath.[38] In addition, it was proven that regenerative endodontic treatments (RET) are very successful against bacteria from the periapical region, which helps in localized lesions healing, thus avoiding the need for apical surgery.[39]

However, PRF has several disadvantages, such as placement difficulty due to its jelly consistency. It may require some special equipment.[26] In addition, extra time to draw blood and centrifuge it prior to insertion into the root canals is required.[40]

\section{Sealing of the access cavity:}

The significance of a good coronal restoration following RET should not be overlooked. The access cavity 
should be restored using a material that seals it against bacteria.[34]

Mineral trioxide aggregate (MTA) is currently the material of choice for achieving coronal sealing in regenerative procedures thanks to its favorable physical and biological properties.[41]

It is a hydrophilic bioceramic that could be set even in the presence of blood. Once set, it is highly resistant to bacterial penetration and it provides signaling molecules for the growth of stem cells.[7] A minimum of 4 $\mathrm{mm}$ of MTA is necessary to ensure a good seal.[11,30]

The most common disadvantage of MTA is crown discoloration in the esthetic zone. To minimize this side effect, dentin bonding of the pulp chamber[16] or the use of other bioceramic materials, such as Biodentine is recommended.[30]

In our present case, Biodentine was used as a coronal seal directly over PRF. We benefited from its high mechanical properties to strengthen the crown which was weakened after odontoma elimination.

\section{Outcomes of revascularization therapy:}

The revascularization therapy outcomes can be evaluated at four levels:

1-Clinical evidence of periapical healing:

This includes the absence and/ or disappearance of sensitivity to percussion or palpation and the absence of sinus tracts and swelling.[23]

In this regard, the PRF regenerative technique is able to promote growth factor release, thus creating a continuous healing process.[42]

In the present case, the tooth was asymptomatic during 8 months of follow-up with the disappearance of the sinus tract after the first appointment.

2-Radiographic evidence of periapical healing and root development:

This includes complete healing of the periapical lesion, an increase in root length, an increase in root wall thickness, and the formation of a radiographic apex.

However, these four conditions may not always be achieved. In addition, they are not essential for the treatment success.[43]

Peter's finding suggests that periapical lesion healing response is $88.9 \%$ for blood clot revascularization techniques and $100 \%$ for both PRP and PRF.[40]

In fact, it has been proven that PRF recruits cells to the site of injury, induces cell differentiation, initiates vascular ingrowth, stimulates collagen and protein synthesis, controls local inflammatory process, increases alkaline phosphatase activity, and consequently improves soft and hard tissues healing.[18,44]
In the present case, we report periapical healing in only three months as observed in the periapical radiograph. According to previous studies, this could be attributed to the sustained release of growth factors from PRF (over a period of 7 to 14 days).[37] Immature teeth can have very thin dentin walls. Once the thickness exceeds $1.5 \mathrm{~mm}$, the tooth will have an improved fracture resistance.[45]

In this regard, an essential requirement for this regenerative therapy is to accomplish dentinal wall thickening to strengthen immature teeth and to help prevent fractures. Kahler et al suggested longer review periods in regeneration cases because in their study, continued root maturogenesis was observed in two cases over a 36-month follow-up period.[46]

Some studies have concluded that the duration of pulp necrosis is a very important factor for apexogenesis. A long period of necrotic tooth might destroy the cells capable of pulp regeneration. Unfortunately, this condition cannot be expected.[47]

In the worst conditions, asymptomatic teeth without radiographic evidence of periapical healing and root development may be left as space maintainers until a suitable decision is taken.[23]

In their review, Conde et al found that the survival rate in the revascularized group was $100 \%$ compared to MTA plug (95\%) and $\mathrm{Ca}(\mathrm{OH}) 2$ apexification (77.2\%).[48]

To conclude, in a recent randomized clinical trial, a comparison of the healing capacity between PRP, PRF, and induced bleeding in the revascularization techniques found that the three groups are comparable on the level of lateral wall thickening, root lengthening, and response to vitality testing.[2]

In the present case, neither wall thickening, nor apical closure were found until the last follow-up visit ( 8 months). These results should be interpreted with caution due to the short follow-up periods. In fact, multiple clinical studies of regenerative endodontic treatment have reported a high success rate over a maximum follow-up period of 12-19 months.[22]

3-A positive response to pulp vitality testing:

This indicates a high success level, and it means the innervation of the root canal space.

The presence of sensitivity and positive response to electric testing are suggestive of vital pulp-like tissue formation with innate and adaptive immune defense mechanisms. [49]

Negative responses to vitality testing may be attributed to the presence of a thick layer of MTA or Biodentine and coronal restorative materials.[50] 
Doppler flowmetry is well-recommended for follow-up in case of revascularization treatment.[51]

4-Histological evidence of dentin-pulp regeneration:

The findings include the ingrowth of cementum and bone into the root canal space with deposition of cementum without dentin for the narrowing of the root canals and apices.[23] Another research showed that the tissue found in the pulp space is more similar to the periodontal ligament than to the pulp tissue.[37]

Furthermore, a fibrous non-mineralized connective tissue with different degrees of inflammation and dystrophic calcifications was observed.[52] However, regeneration of the dentin-pulp complex within the root canals was not revealed.[23]

\section{Advantages over current treatment modalities:}

1. Unlike calcium hydroxide-induced apexification, obturation of the canal is not required.[53]

2. Ensures apexogenesis with continued root development (root lengthening) and root strengthening with deposition of new hard tissue, resulting in the reinforcement of lateral dentinal walls and preventing tooth fracture.[54]

\section{Limitations:}

1. A revitalized tooth may be susceptible to further pulp disease (calcification) and may require retreatment which will be difficult. [55]

2. Revascularization is not the right treatment option if post and core are required for the final restorative step.

3. The concentration and composition of the cells trapped in the PRF clot are unpredictable. This limitation can be overcome by the use of platelet concentrates. PRP is an ideal scaffold for revascularization. [56,57]

4. Patient's compliance can be a problem as the treatment can take from several months to years with multiple clinical appointments. [30]

5. Even in successful cases, increased dentin wall thickness occurs at the apical and the middle third and not at the cervical one-third region, which is more prone to fracture.[30]

\section{Conclusion}

DI is a developmental anomaly showing a wide range of spectrum. The clinician should be aware of the presence of this abnormality as it has the potential to cause necrosis and apical inflammatory diseases. In fact, the condition can be more complicated if we are faced with an immature permanent tooth with necrotic pulp. In this regard, regenerative endodontic treatment and the application of blood venous derivatives, such as PRF can be indicated to benefit from their efficient regenerative potential.

Financial Disclosure: Nil.

Conflict of Interest: None declared.

\section{References}

1. Mohan A, Krishnan U, Akber M, Nair MG, Balan A. Successful management of a case of true radicular dens invaginatus using platelet-rich fibrin and guided tissue regeneration. Aust Endod J 2020;46(1):94-100 doi:10.1111/aej.12377

2. Shivashankar VY, Johns DA, Maroli RK, et al. Comparison of the effect of PRP, PRF and induced bleeding in the revascularization of teeth with necrotic pulp and open apex: A triple blind randomized clinical trial. J Clin Diagn Res 2017;11(6):ZC34-ZC39 doi:10.7860/JCDR/2017/22352.10056

3. Vier-Pelisser FV, Pelisser A, Recuero LC, Só MV, Borba MG, Figueiredo JA. Use of cone beam computed tomography in the diagnosis, planning and follow up of a type III dens invaginatus case. Int Endod J 2012;45(2):198-208 doi:10.1111/j.13652591.2011.01956.x

4. Piresa MD, Baruwaa AO, Martinsa JN, Quaresmaa SA, da Costaa RP, Ginjeira A. Endodontic management of developmental anomalies: conservation of invaginated tissues in Type II dens invaginatus - case series. Rev Port Estomatol Med Dent Cir Maxilofac 2019;60:1-10 doi:10.24873/j.rpemd.2019.03.442

5. Pradhan B, Gao Y, He L, Li J. Non-surgical removal of dens invaginatus in maxillary lateral incisor using CBCT: Twoyear follow-up case report. Open Med (Wars) 2019;14:767-771 doi:10.1515/med-2019-0089

6. Srivastava R, Verma PK, Tripathi V, Tripathi P, Singh AR. Management of Oehlers type II dens in dente with open apex and alveolar bone defect. J Clin Diagn Res 2016;10(11):ZJ05-ZJ06 doi:10.7860/JCDR/2016/22373.8808

7. Silberman A, Cohenca N, Simon JH. Anatomical redesign for the treatment of dens invaginatus type III with open apexes: a literature review and case presentation. J Am Dent Assoc 2006;137(2):180-185 doi:10.14219/jada.archive.2006.0142

8. George R, Moule AJ, Walsh LJ. A rare case of dens invaginatus in a mandibular canine. Aust Endod J 2010;36(2):83-86 doi:10.1111/j.1747-4477.2010.00237.x

9. Zengin AZ, Sumer AP, Celenk P. Double dens invaginatus: report of three cases. Eur J Dent 2009;3(1):67-70

10. Stamfelj I, Kansky AA, Gaspersic D. Unusual variant of type 3 dens invaginatus in a maxillary canine: a rare case report. J Endod 2007;33(1):64-68 doi:10.1016/j.joen.2006.06.010

11. Tachibana H, Matsumoto K. Applicability of X-ray computerized tomography in endodontics. Endod Dent Traumatol 1990;6(1):16-20 doi:10.1111/j.1600-9657.1990.tb00381.x 
12. Kaneko T, Sakaue H, Okiji T, Suda H. Clinical management of dens invaginatus in a maxillary lateral incisor with the aid of conebeam computed tomography--a case report. Dent Traumatol 2011;27(6):478-483 doi:10.1111/j.1600-9657.2011.01021.x

13. Rocha Neto PC, Castro De Oliveira L, De Oliveira MD, Pinto L P , Vasconcelos Gurge lB C, Galvao C. Dens invaginatus: case report. RGO, Rev Gaúch Odontol, Porto Alegre, 2015;63:219-226

14. Abazarpour R, Parirokh M, Farhadi A, Jalali Z, Kheirabadi N. Successful ultra-conservative management of a mandibular premolar with dens invaginatus. Iran Endod J 2017;12(3):390-395 doi:10.22037/iej.v12i3.16559

15. Pai SF, Yang SF, Lin LM. Nonsurgical endodontic treatment of dens invaginatus with large periradicular lesion: a case report. J Endod 2004;30(8):597-600 doi:10.1097/00004770-20040800000009

16. Reynolds K, Johnson JD, Cohenca N. Pulp revascularization of necrotic bilateral bicuspids using a modified novel technique to eliminate potential coronal discolouration: a case report. Int Endod J 2009;42(1):84-92 doi:10.1111/j.13652591.2008.01467.x

17. Er K, Kuştarci A, Ozan U, Taşdemir T. Nonsurgical endodontic treatment of dens invaginatus in a mandibular premolar with large periradicular lesion: a case report. J Endod 2007;33(3):322324 doi:10.1016/j.joen.2006.09.001.

18. Dohan DM, Choukroun J, Diss A, et al. Platelet-rich fibrin (PRF): a second-generation platelet concentrate. Part I: technological concepts and evolution. Oral Surg Oral Med Oral Pathol Oral Radiol Endod 2006;101(3):e37-e44 doi:10.1016/j. tripleo.2005.07.008

19. Srivastava R, Verma PK, Tripathi V, Tripathi P, Singh AR. Management of Oehlers type II dens in dente with open apex and alveolar bone defect. J Clin Diagn Res 2016;10(11):ZJ05-ZJ06 doi:10.7860/JCDR/2016/22373.8808

20. Huang GT, Sonoyama W, Liu Y, Liu H, Wang S, Shi S. The hidden treasure in apical papilla: the potential role in pulp/dentin regeneration and bioroot engineering. J Endod 2008;34(6):645-651 doi:10.1016/j.joen.2008.03.001

21. Sathorn C, Parashos P. Contemporary treatment of class II dens invaginatus. Int Endod J 2007;40(4):308-316 doi:10.1111/j.13652591.2007.01205.x

22. Almutairi W, Yassen GH, Aminoshariae A, Williams KA, Mickel A. Regenerative Endodontics: A Systematic Analysis of the Failed Cases. J Endod 2019;45(5):567-577 doi:10.1016/j. joen.2019.02.004

23. Bezgin T, Sönmez H. Review of current concepts of revascularization/revitalization. Dent Traumatol 2015;31(4):267-273 doi:10.1111/edt.12177

24. Haapasalo M, Shen Y, Qian W, Gao Y. Irrigation in endodontics. Dent Clin North Am 2010;54(2):291-312 doi:10.1016/j. cden.2009.12.001

25. Martin DE, De Almeida JF, Henry MA, et al. Concentrationdependent effect of sodium hypochlorite on stem cells of apical papilla survival and differentiation. J Endod 2014;40(1):51-55 doi:10.1016/j.joen.2013.07.026
26. Nagaveni NB, Pathak S, Poornima P, Joshi JS. Revascularization induced maturogenesis of non-vital immature permanent tooth using platelet-rich-fibrin: A Case Report. J Clin Pediatr Dent 2016;40(1):26-30 doi:10.17796/1053-4628-40.1.26

27. Nagata JY, Soares AJ, Souza-Filho FJ, et al. Microbial evaluation of traumatized teeth treated with triple antibiotic paste or calcium hydroxide with $2 \%$ chlorhexidine gel in pulp revascularization. J Endod 2014;40(6):778-783 doi:10.1016/j.joen.2014.01.038

28. Yassen GH, Vail MM, Chu TG, Platt JA. The effect of medicaments used in endodontic regeneration on root fracture and microhardness of radicular dentine. Int Endod J 2013;46(7):688695 doi:10.1111/iej.12046

29. Fahmy SH, Hassanien EES, Nagy MM, et al. Investigation of the regenerative potential of necrotic mature teeth following different revascularisation protocols. Aust Endod J 2017;43(2):73-82 doi:10.1111/aej.12210

30. Velmurugan N. Revascularization of necrotic immature permanent teeth: An update. J Oper Dent Endod 2016;1(1):18-24

31. Ruparel NB, Teixeira FB, Ferraz CC, Diogenes A. Direct effect of intracanal medicaments on survival of stem cells of the apical papilla. J Endod 2012;38(10):1372-1375 doi:10.1016/j. joen.2012.06.018

32. Galler KM, Buchalla W, Hiller KA, et al. Influence of root canal disinfectants on growth factor release from dentin. J Endod 2015;41(3):363-368 doi:10.1016/j.joen.2014.11.021

33. Zeng Q, Nguyen S, Zhang $\mathrm{H}$, et al. Release of growth factors into root canal by irrigations in regenerative endodontics. J Endod 2016;42(12):1760-1766 doi:10.1016/j.joen.2016.04.029

34. Pannu R. Pulp revascularisation - An evolving concept: A review. Int J Appl Dent Sci 2017;3(4):118-121

35. Keswani D, Pandey RK. Revascularization of an immature tooth with a necrotic pulp using platelet-rich fibrin: a case report. Int Endod J 2013;46(11):1096-1104 doi:10.1111/iej.12107

36. Johns DA, Vidyanath S. Revitalization of tooth with necrotic pulp and open apex by using platelet-rich plasma: a case report. J Endod 2011;37(6):743-744 doi:10.1016/j.joen.2011.03.018

37. Nagaveni NB, Poornima P, Joshi JS, Pathak S, Nandini DB. Revascularization of immature, nonvital permanent tooth using platelet-rich fibrin in children. Pediatr Dent 2015;37(1):1-6

38. Huang GT, Sonoyama W, Liu Y, Liu H, Wang S, Shi S. The hidden treasure in apical papilla: the potential role in pulp/dentin regeneration and bioroot engineering. J Endod 2008;34(6):645-651 doi:10.1016/j.joen.2008.03.001

39. Pinto N, Harnish A, Cabrera C, Andrade C, Druttman T, Brizuela C. An innovative regenerative endodontic procedure using leukocyte and platelet-rich fibrin associated with apical surgery: A case report. J Endod 2017;43(11):1828-1834 doi:10.1016/j. joen.2017.07.002

40. Murray PE. Platelet-rich plasma and platelet-rich fibrin can induce apical closure more frequently than blood-clot revascularization for the regeneration of immature permanent teeth: A meta-analysis of clinical efficacy. Front Bioeng Biotechnol 2018;6:139 doi:10.3389/fbioe.2018.00139 
41. Banchs F, Trope M. Revascularization of immature permanent teeth with apical periodontitis: new treatment protocol?. J Endod 2004;30(4):196-200 doi:10.1097/00004770-200404000-00003

42. Simonpieri A, Del Corso M, Sammartino G, Dohan Ehrenfest DM. The relevance of Choukroun's platelet-rich fibrin and metronidazole during complex maxillary rehabilitations using bone allograft. Part I: a new grafting protocol. Implant Dent 2009;18(2):102-111 doi:10.1097/ID.0b013e318198cf00

43. American Association of Endodontics. Clinical considerations for a regenerative procedure. Available at: https:// www.aae.org/specialty/wpcontent/uploads/sites/2/2018/06/ ConsiderationsForRegEndo_AsOfApril2018.pdf Accessed 11 May 2020

44. Huang FM, Yang SF, Zhao JH, Chang YC. Platelet-rich fibrin increases proliferation and differentiation of human dental pulp cells. J Endod 2010;36(10):1628-1632 doi:10.1016/j. joen.2010.07.004

45. Haralur SB, Al-Qahtani AS, Al-Qarni MM, Al-Homrany RM, Aboalkhair AE. Influence of remaining dentin wall thickness on the fracture strength of endodontically treated tooth. J Conserv Dent 2016;19(1):63-67 doi:10.4103/0972-0707.173201.

46. Kahler B, Mistry S, Moule A, et al. Revascularization outcomes: a prospective analysis of 16 consecutive cases. J Endod. 2014;40(3):333-338 doi:10.1016/j.joen.2013.10.032

47. Nosrat A, Homayounfar N, Oloomi K. Drawbacks and unfavorable outcomes of regenerative endodontic treatments of necrotic immature teeth: a literature review and report of a case. J Endod 2012;38(10):1428-1434 doi:10.1016/j.joen.2012.06.025

48. Conde MCM, Chisini LA, Sarkis-Onofre R, Schuch HS, Nör JE, Demarco FF. A scoping review of root canal revascularization: relevant aspects for clinical success and tissue formation. Int Endod J 2017;50(9):860-874 doi:10.1111/iej.12711
49. Nageh M, Ahmed GM, El-Baz AA. Assessment of regaining pulp sensibility in mature necrotic teeth using a modified revascularization technique with platelet-rich fibrin: A clinical study. J Endod 2018;44(10):1526-1533 doi:10.1016/j.joen.2018.06.014

50. Torabinejad M, Turman M. Revitalization of tooth with necrotic pulp and open apex by using platelet-rich plasma: a case report. J Endod 2011;37(2):265-268 doi:10.1016/j.joen.2010.11.004

51. Fouad AF, Nosrat A. Pulp regeneration in previously infected root canal space. Endod Topics 2013;28:24-37 doi:10.1111/ etp.12039

52. Becerra P, Ricucci D, Loghin S, Gibbs JL, Lin LM. Histologic study of a human immature permanent premolar with chronic apical abscess after revascularization/revitalization. J Endod 2014;40(1):133-139 doi:10.1016/j.joen.2013.07.017

53. Udhya J, Varadharaja MM. Revascularization of dental pulp Contemporary review. Int J Res Dent 2013;3:1-6

54. Shah N, Logani A, Bhaskar U, Aggarwal V. Efficacy of revascularization to induce apexification/apexogensis in infected, nonvital, immature teeth: a pilot clinical study. J Endod 2008;34(8):9191157 doi:10.1016/j.joen.2008.05.001

55. Chen MY, Chen KL, Chen CA, Tayebaty F, Rosenberg PA, Lin LM. Responses of immature permanent teeth with infected necrotic pulp tissue and apical periodontitis/abscess to revascularization procedures. Int Endod J 2012;45(3):294-305 doi:10.1111/j.13652591.2011.01978.x

56. Murray PE, Garcia-Godoy F, Hargreaves KM. Regenerative endodontics: a review of current status and a call for action. J Endod 2007;33(4):377-390 doi:10.1016/j.joen.2006.09.013

57. Spångberg LS. The Emperor's new cloth. Oral Surg Oral Med Oral Pathol Oral Radiol Endod 2009;108(5):643-644 doi:10.1016/j.tripleo.2009.08.001 